\title{
ESCALAS DE MEDIÇÃO DO QUOCIENTE DE EMPATIA/ SISTEMATIZAÇÃO: UM ENSAIO DE VALIDAÇÃO PARA A POPULAÇÃo PORTUGUESA ${ }^{1}$
}

\author{
Joana Rodrigues ${ }^{2}$ \\ Albino Lopes ${ }^{3}$ \\ Jean-Christophe Giger ${ }^{4}$ \\ Alexandra Gomes ${ }^{4}$ \\ Joana Santos ${ }^{4}$ \\ Gabriela Gonçalves ${ }^{4}$
}

\begin{abstract}
Resumo: A teoria da empatia - sistematização, desenvolvida por Baron-Cohen (2002), assume a existência de dois principais tipos cognitivos, um mais característico do género feminino (com maior capacidade para empatizar) e outro mais característico do género masculino (com maior capacidade para sistematizar). Para avaliar estes conceitos, Baron-Cohen e os seus colegas (2003) desenvolveram as escalas do Quociente de Empatia (QE) e do Quociente de Sistematização (QS). O principal objectivo deste estudo consistiu em validar a versão curta da escala do QE (desenvolvida por Wakabayashi et al., 2006) para a população portuguesa, utilizando uma amostra de 506 participantes. Realizou-se uma análise factorial exploratória para a escala do QE, tendo sido encontrados quatro factores na escala do QE, os quais foram denominados de 1) Empatia Cognitiva; 2) Reactividade Emocional; 3) Capacidades Sociais; e 4) Dificuldades Empáticas.
\end{abstract}

Palavras-chave: Quociente de Empatia; Quociente de Sistematização; Tipos cognitivos; Análise factorial exploratória

Measure scales of Empathizing/Systemizing Quotient: A validation test for the Portuguese population (Abstract): The empathizing - systemizing theory, developed by Baron-Cohen (2002), assumes the existence of two main cognitive styles, one more characteristic of female gender (with greater capacity to empathize), and

\footnotetext{
${ }^{1}$ Nota: Artigo revisto e aceite para publicação sob a responsabilidade da anterior direcção da revista Psicologia.

${ }^{2}$ Universidade do Algarve. Email: joanarodri@gmail.com

3 ISCTE-IUL.

${ }^{4}$ Universidade do Algarve

PSICOLOGIA, Vol. XXV (1), 2011, Edições Colibri, Lisboa, pp. 73-89
} 
the other more characteristic of male gender (with greater capacity to systemize). To assess these concepts, Baron-Cohen and his colleagues (2003) developed the Empathy Quotient (EQ) and Systemizing Quotient (SQ) scales. This study central aim was to validate the short version of the EQ scale (developed by Wakabayashi et al., 2006) for the Portuguese population, using a sample of 506 participants. It was carried out an exploratory factor analysis EQ scale, and there was found four factors in the EQ scale, which were denominated by 1) Cognitive empathy; 2) Emotional reactivity; 3) Social skills; and 4) Empathic difficulties.

Keywords: Systemizing quotient; Empathy quotient; Cognitive styles; Exploratory factor analysis

\section{Introdução}

Ao longo das últimas décadas o conceito de empatia tem sido alvo de inúmeros estudos pela sua crescente importância a vários níveis, principalmente a nível profissional, sendo muitas as áreas profissionais em que a empatia é um factor imprescindível. O exercício de funções como, por exemplo, a medicina, a enfermagem, a gestão, o comércio, entre outras, envolvem uma contínua interacção social por parte dos profissionais, que devem conseguir colocar-se no lugar de outra pessoa e responder de forma adequada aos seus pensamentos e sentimentos. Além do conceito de empatia, neste estudo será também abordado o conceito de sistematização, bem mais recente. A sistematização diz respeito à capacidade que uma pessoa tem de conseguir prever o comportamento de um sistema, considerando as respectivas regras. Por exemplo, se uma pessoa estiver a conduzir um carro deve saber que, com mudança posta, se carregar no travão a fundo sem carregar na embraiagem, o carro vai abaixo. Este conceito tem igualmente a sua importância a nível profissional, já que existem áreas de actividade que estão associadas a uma maior capacidade para sistematizar (e.g., engenharia informática, engenharia química, medicina, etc.).

Neste estudo serão abordados estes dois conceitos, reunindo esforços para que seja possível contribuir para a avaliação destas duas capacidades através da validação de duas escalas desenvolvidas por Wakabayashi e colaboradores (2006).

\section{Conceito de Empatia}

Titchener foi o primeiro autor a desenvolver o termo "empatia" com o propósito de traduzir a palavra alemã Einfuhlung, que significa a projecção de si mesmo no que se está a observar (Titchener, 1909, cit. in Hakansson, 2003). 
O conceito de empatia foi, entretanto, muito estudado, o que originou diferentes definições e perspectivas relativamente divergentes. As influências cognitivistas contribuíram de forma notável para o rápido desenvolvimento deste conceito, ao defenderem que os indivíduos têm capacidades para descentrarem a sua atenção e para ver a perspectiva dos outros (Mead, 1982) e inferir os seus estados mentais (Köhler, 1992). Recentemente foi desenvolvido o conceito de "teoria da mente" (Wellman, 1990; Baron-Cohen, 1995, cit. in Baron-Cohen \& Wheelwright, 2004) que pressupõe a tomada de perspectiva de outra pessoa e a atribuição de um estado mental à mesma. É também importante referir que este processo inferencial abrange igualmente a capacidade de predizer o comportamento ou o estado mental de outrem (Dennett, 1987, cit. in Baron-Cohen \& Wheelwright, 2004).

No entanto, para além da componente cognitiva, o conceito de empatia envolve também uma componente afectiva. De acordo com Lawrence e colaboradores (2004), uma resposta emocional, para ser considerada como "empatia afectiva", tem de responder de forma adequada ao estado mental que está a ser observado. Estas respostas podem ser classificadas como paralelas (por exemplo, alguém que se sente triste ao sentir a tristeza de outra pessoa), ou reactivas (como a simpatia ou compaixão por outra pessoa, envolvendo mais do que a igualdade de sentimentos - Davis, 1980). Existe ainda outra resposta emocional que não é considerada empatia real, denominada de "angústia pessoal", como por exemplo sentir felicidade ao observar a infelicidade de outrem (Davis, 1980). Segundo Batson (1987), este tipo de resposta emocional envolve uma motivação egoísta para ver a sua própria angústia reduzida, enquanto a empatia envolve uma motivação altruísta para tentar reduzir as necessidades dos outros. A diferença entre estas duas respostas é que a "angústia pessoal" apresenta uma orientação para si próprio, enquanto a empatia envolve uma orientação para os outros.

A empatia é um atributo muito importante nas interacções sociais, pois permite-nos captar como outra pessoa se está a sentir ou o que poderá estar a pensar. Só desta forma somos capazes de deduzir as intenções dos outros, predizer os seus comportamentos e sentir de forma próxima o que outra pessoa possa estar a sentir. No entanto, importa salientar que a empatia pode ser considerada como um traço de personalidade, podendo variar em função do estado emocional dos indivíduos (Baron-Cohen \& Wheelwright, 2004). Por exemplo, se um indivíduo está irado, provavelmente será mais difícil de compreender o ponto de vista do outro.

\section{Conceito de Sistematização}

A sistematização diz respeito à aptidão que uma pessoa tem para desenvolver um sistema e de analisar as suas variáveis, considerando as 
regras subjacentes que dirigem o comportamento desse sistema. Esta aptidão é considerada um processo indutivo, pois começa-se por observar a relação causal que possa existir entre as variáveis do sistema. No caso de se verificar realmente uma associação, elabora-se então uma regra sobre esse aspecto do sistema e pode-se predizer os seus resultados (se fizer X então A acontece). No entanto, se for observada uma excepção à regra, esta deve ser submetida a uma revisão ou então deve ficar retida. Desta forma, é possível predizer e controlar o comportamento do sistema (Baron-Cohen, 2002; Baron-Cohen et al., 2003; Wakabayashi et al., 2006).

Um sistema é definido como algo que recebe informações, que são posteriormente operacionalizadas de diversas formas, de maneira a obter como resultado outras informações que têm de estar de acordo com a regra previamente definida.

De acordo com Baron-Cohen (2002, 2003), existem pelo menos seis tipos de sistemas que se baseiam no mesmo processo: Input $\rightarrow$ Operação $\rightarrow$ Output. O input é definido como o estado inicial do sistema, sobre o qual são tomadas certas acções (operações) que transformam esse estado no output, um estado já modificado. Os tipos de sistemas referidos por estes autores são os técnicos (e.g., computador, instrumento musical, meio de transporte); naturais (e.g., maré, frente meteorológica, planta); abstractos (e.g., sintaxe, programa informático, matemática); sociais (e.g., sistema legal, negócio, eleição política); organizáveis (e.g., taxonomia, livraria, colecção); e de ordem motora (e.g., técnica para tocar um instrumento musical, desempenho, técnica de desporto).

\section{Teoria da Empatia - Sistematização}

De acordo com Baron-Cohen (2002), a empatia e a sistematização são duas das principais dimensões cognitivas no que diz respeito à definição do cérebro masculino e feminino. Segundo estes autores é possível pensar em cinco tipos de cérebros (ver figura 1). 
Figura 1. Os tipos de cérebro de acordo com as dimensões de empatia (E) e de sistematização (S). Retirado de Baron-Cohen, 2002.

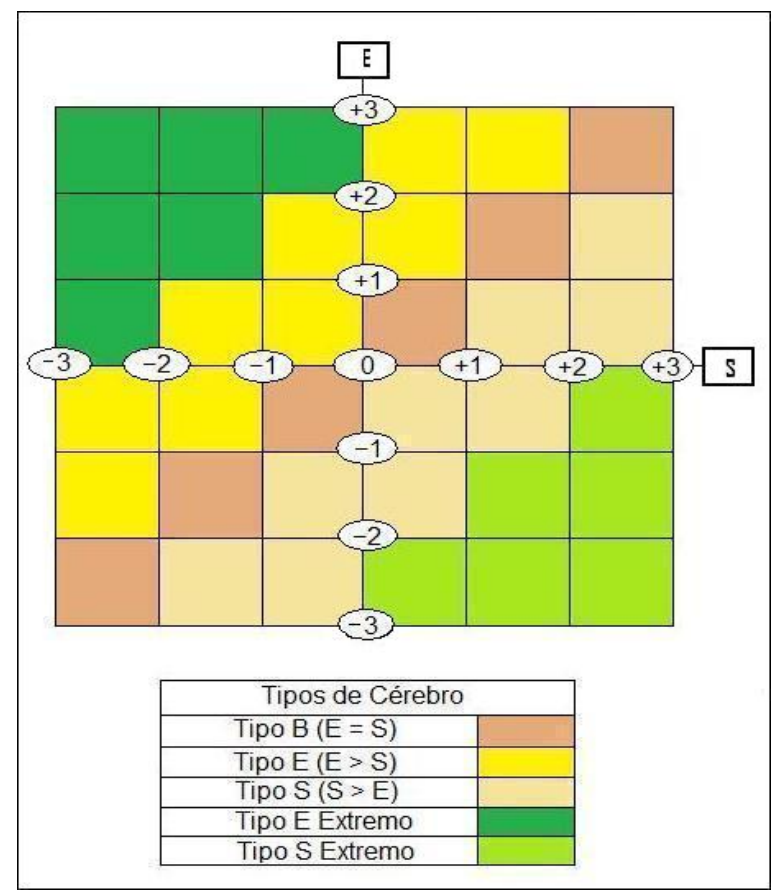

\section{- Tipo E}

Indivíduos cuja capacidade de empatia está mais desenvolvida do que a capacidade de sistematização, nomeado pelos autores como "cérebro feminino".

\section{- Tipo S}

Indivíduos cuja capacidade de sistematização se encontra mais desenvolvida do que a capacidade de empatia, designado pelos autores como "cérebro masculino".

\section{- Tipo B}

Indivíduos cujas capacidades de sistematização e de empatia estão igualmente desenvolvidas, designado pelos autores como "cérebro equilibrado". 


\section{- Tipo E Extremo}

Indivíduos com o cérebro feminino muito desenvolvido, com uma capacidade de empatia muito desenvolvida e uma capacidade de sistematização muito pouco desenvolvida.

\section{- Tipo S Extremo}

Indivíduos com o cérebro masculino muito desenvolvido, estando a sua capacidade de sistematização muito desenvolvida e a sua capacidade de empatia muito pouco desenvolvida.

\section{Objectivo do Estudo}

O principal objectivo do estudo consistiu em validar a versão curta da escala do Quociente de Empatia (desenvolvida por Wakabayashi et al., 2006) para a população portuguesa. Além deste objectivo, pretende-se também observar o tipo de correlação existente entre a escala e subescalas do QE e a escala do QS.

\section{Método}

\section{Amostra}

A amostra do presente estudo é composta por 506 participantes, sendo $64.2 \%$ do género feminino e $35.8 \%$ do género masculino. A idade média dos participantes é de 33.87 , com um desvio padrão de 11.66, oscilando entre os 18 e os 71 anos de idade.

Trata-se de uma amostra de conveniência que abrange indivíduos naturais de várias localidades de Portugal, com diversas habilitações literárias, áreas de formação e tipos de profissão. Os participantes são na sua maioria naturais das regiões do Algarve (45.9\%) e da Estremadura (30.2\%).

\section{Instrumentos}

As escalas do Quociente de Empatia e do Quociente de Sistematização foram originalmente desenvolvidas por Baron-Cohen e colaboradores (2003), sendo ambas constituídas por 60 questões.

Posteriormente, Lawrence e colaboradores (2004), ao concluírem que a escala do Quociente de Empatia possuía validade e fiabilidade para ser utilizada, realizaram uma análise factorial confirmatória. Esta análise deu origem a três factores distintos, compostos na sua totalidade por 28 itens. O primeiro factor, composto por 11 itens, foi denominado de "empatia cognitiva" e diz respeito à capacidade de avaliação de estados afectivos. O segundo 
factor, composto por 11 itens, é referido como "reactividade emocional" por reflectir a tendência para responder adequadamente aos estados mentais de outras pessoas. Por fim, o terceiro factor, constituído por 6 itens, foi designado de "capacidades sociais", por implicar a capacidade de julgar situações sociais de forma intuitiva e espontânea.

Em 2006, Muncer e Ling realizaram um estudo com a escala do Quociente de Empatia de 28 itens de Lawrence e colaboradores (2004). Através desta escala construíram uma nova versão de 15 itens, em que cada factor comportava 5 itens. Apesar de terem obtido resultados razoáveis espera-se pela confirmação de novos estudos.

Ainda em 2006, Wakabayashi e colaboradores desenvolveram duas versões curtas, a partir das escalas originais do Quociente de Empatia (composta por 22 itens) e do Quociente de Sistematização (composta por 25 itens). Foram estes os instrumentos utilizados no presente estudo. Note-se que, de forma a poderem realizar-se comparações a nível estatístico, serão utilizados os números dos itens originais (das escalas de 60 itens). Em anexo são apresentadas as versões originais e as versões curtas.

Os itens de ambos os instrumentos foram respondidos numa escala de 4 pontos, que oscilam entre 1 (Concordo Fortemente) e 4 (Discordo Fortemente). Cada participante pode obter 0 pontos (numa resposta não empática/não sistemática), 1 ponto (numa resposta ligeiramente empática/sistemática), ou 2 pontos (numa resposta fortemente empática/sistemática). A sua pontuação máxima pode variar entre 0 e 44 pontos (no caso do Quociente de Empatia), e entre 0 e 50 pontos (no caso do Quociente de Sistematização).

Ambas as escalas foram inicialmente traduzidas de inglês para português, sendo posteriormente traduzidas de português para inglês de forma a satisfazer a validade facial. Esta última tradução foi realizada por um indivíduo português que se formou em Inglaterra e que domina perfeitamente a língua inglesa. Após a comparação das versões inglesas procedeu-se a algumas alterações nas versões portuguesas para que, sem alterar o sentido das frases, se mantivesse um português fluente. Solicitou-se então a 20 participantes (pré-teste) que respondessem às versões portuguesas, cujos coeficientes alpha de Cronbach foram ambos de 0.84 .

\section{Procedimento}

Foi solicitado aos participantes que respondessem às duas escalas, informando que o preenchimento das escalas era protegido pelo anonimato e que devia ter uma duração aproximada de 15 minutos. As escalas foram respondidas individualmente, apesar de em alguns casos terem sido aplicadas a grupos de pessoas. Nestes casos era pedido aos participantes que não conversassem entre eles durante o preenchimento das escalas. As escalas 
foram aplicadas em diversas situações, nomeadamente em turmas de alunos universitários, nos locais de trabalho dos respondentes (bancos, estabelecimentos de comércio, hospitais, e outros), e indivíduos abordados ao acaso na rua e em estabelecimentos alimentares. A todos os participantes foi explicado, posteriormente, o objectivo do estudo.

\section{Análise e Discussão dos Resultados}

Para a análise dos dados foi utilizado o programa estatístico SPSS (versão 16).

\section{Análise Factorial Exploratória}

Primeiramente foi utilizada uma análise factorial exploratória de componentes principais, com rotação varimax, para analisar o número de componentes existentes na versão curta da escala do Quociente de Empatia.

Tabela 1: Variância explicada pelas 5 componentes principais

\begin{tabular}{cccc}
\hline $\begin{array}{c}\text { Componentes } \\
\text { Principais }\end{array}$ & Valor-próprio & \% variância & $\begin{array}{c}\text { \% variância } \\
\text { acumulada }\end{array}$ \\
\hline 1 & 5.857 & 26.624 & 26.624 \\
2 & 1.967 & 8.943 & 35.568 \\
3 & 1.489 & 6.766 & 42.334 \\
4 & 1.134 & 5.154 & 47.487 \\
5 & 1.032 & 4.690 & 52.177 \\
\hline
\end{tabular}

A análise mostra a existência de 5 componentes principais com valores-próprios superiores a 1, explicando $52.177 \%$ da variância total. Observa-se a presença de correlações significativas entre as componentes, uma vez que se obteve um KMO de .892 e um qui-quadrado, no teste de Esfericidade de Bartlett de 2858.35, com 231 graus de liberdade e uma significância de 0 . Tendo em conta estes resultados é possível dar continuidade à análise factorial exploratória (Reis, 2001).

Todos os 22 itens do questionário contribuem de forma significativa para a variância do factor a que correspondem, saturando-o a mais de 0.4. Após a observação dos itens por factor, foram aplicadas as mesmas designações dadas por Lawrence e colegas (2004) e por Muncer e Ling (2006), ape- 
sar de nem todos os itens coincidirem com as propostas destes autores. Assim, o factor 1 será relativo à empatia cognitiva; o factor 2 à reactividade emocional; o factor 3 às capacidades sociais. $O$ factor 4 que não está presente nos estudos referidos anteriormente, foi denominado de dificuldades empáticas.

Tabela 2: Matriz dos pesos factoriais

\begin{tabular}{lcccccc}
\hline & Comunalidade & Factor & Factor & Factor & Factor & Factor \\
\hline QE58 &, 585 & $\mathbf{1}$ & 2 & 3 & 4 & 5 \\
QE925 &, 564 &, 068 &, 214 &, 003 &, 005 \\
QE54 &, 548 & $\mathbf{, 6 8 0}$ &, 063 &, 259 &, 100 &,- 062 \\
QE36 &, 651 & $\mathbf{, 6 7 9}$ &, 377 &, 060 &, 186 &, 094 \\
QE55 &, 503 & $\mathbf{, 5 2 2}$ &, 182 &, 444 &, 001 &,- 012 \\
QE59 &, 511 &, 089 & $\mathbf{, 7 0 0}$ &, 104 &, 014 &,- 049 \\
QE6 &, 489 &, 079 & $\mathbf{, 6 8 0}$ &, 089 &,- 021 &, 113 \\
QE43 &, 481 &, 204 & $\mathbf{, 6 2 0}$ &, 195 &, 129 &,- 023 \\
QE22 &, 546 &, 465 & $\mathbf{, 5 1 0}$ &,- 115 &, 134 &, 198 \\
QE52 &, 539 &, 445 & $\mathbf{4 5 6}$ &, 338 &, 074 &, 112 \\
QE1 &, 534 &, 247 &, 000 & $\mathbf{6 4 6}$ &, 005 &, 234 \\
QE41 &, 544 &, 251 &, 228 & $\mathbf{, 6 3 9}$ &, 104 &, 101 \\
QE44 &, 534 &,- 062 &, 414 & $\mathbf{, 5 6 4}$ &, 152 &,- 132 \\
QE19 &, 443 &, 369 &,- 034 & $\mathbf{, 5 3 7}$ &, 124 &, 039 \\
QE26 &, 503 &, 356 &, 322 & $\mathbf{, 5 0 0}$ &, 084 &, 120 \\
QE14 &, 487 &, 043 &, 064 &, 140 & $\mathbf{, 6 3 1}$ &, 252 \\
QE15 &, 420 &, 070 &, 177 &, 014 & $\mathbf{, 6 1 2}$ &,- 092 \\
QE8 &, 666 &,- 007 &, 054 &, 041 & $\mathbf{6 0 0}$ &, 549 \\
QE29 &, 437 &, 222 &,- 019 &, 078 & $\mathbf{5 9 4}$ &,- 169 \\
QE48 &, 453 &,- 047 &, 374 &, 145 & $\mathbf{5 3 8}$ &,- 020 \\
QE21 &, 301 &, 012 &,- 104 &,- 005 & $\mathbf{5 3 7}$ &, 029 \\
QE35 &, 739 &, 138 &, 063 &, 197 &,- 056 &, $\mathbf{8 2 1}$ \\
\hline & & & & & &
\end{tabular}




\section{Fiabilidade e Consistência Interna dos Instrumentos}

Com o objectivo de analisar a fiabilidade e a consistência interna das escalas e sub-escalas recorreu-se ao coeficiente alpha de Cronbach. As versões curtas das escalas do Quociente de Empatia e do Quociente de Sistematização obtiveram alphas de .85 e de .72, respectivamente, ao passo que Wakabayashi e colaboradores (2006) obtiveram alphas de .90 e de .89 , respectivamente.

Tabela 3: Valores do alpha de Cronbach e correlações item/dimensão para os quatro factores resultantes da análise factorial exploratória

\begin{tabular}{|c|c|c|c|}
\hline Factores & $\begin{array}{c}\text { Correlações } \\
\text { Item/Dimensão }\end{array}$ & $\begin{array}{l}\text { Alpha se o Item } \\
\text { fosse Apagado }\end{array}$ & Alpha \\
\hline \multicolumn{4}{|c|}{ Empatia Cognitiva } \\
\hline 25 & .55 & .77 & \multirow{5}{*}{.80} \\
\hline 36 & .58 & .76 & \\
\hline 54 & .58 & .75 & \\
\hline 55 & .55 & .77 & \\
\hline 58 & .62 & .74 & \\
\hline \multicolumn{4}{|c|}{$\underline{\text { Reactividade Emocional }}$} \\
\hline 06 & .44 & .67 & \multirow{5}{*}{.71} \\
\hline 22 & .43 & .68 & \\
\hline 43 & .50 & .65 & \\
\hline 52 & .51 & .65 & \\
\hline 59 & .47 & .66 & \\
\hline \multicolumn{4}{|c|}{ Capacidades Sociais } \\
\hline 01 & .47 & .65 & \multirow{5}{*}{.70} \\
\hline 19 & .42 & .67 & \\
\hline 26 & .53 & .63 & \\
\hline 41 & .54 & .62 & \\
\hline 44 & .36 & .70 & \\
\hline \multicolumn{4}{|c|}{ Dificuldades Empáticas } \\
\hline 08 & .47 & .59 & \multirow{6}{*}{.66} \\
\hline 14 & .47 & .59 & \\
\hline 15 & .39 & .62 & \\
\hline 21 & .27 & .66 & \\
\hline 29 & .36 & .63 & \\
\hline 48 & .39 & .62 & \\
\hline
\end{tabular}


Conforme se pode observar na tabela anterior, os factores encontrados pela análise factorial exploratória apresentam uma consistência interna bastante razoável tendo em conta o número de itens para cada sub-escala $(\alpha=$ .80 para a empatia cognitiva; $\alpha=.71$ para a reactividade emocional; $\alpha=.70$ para as capacidades sociais; $\alpha=.66$ para as dificuldades empáticas).

Os resultados obtidos, bem como a análise dos coeficientes alpha se os itens fossem apagados, permitem especular uma melhor adequação da escala do Quociente de Empatia a um modelo de quatro factores.

Note-se que o item 35 ("Não tendo a achar as situações sociais confusas") foi deixado de parte, uma vez que surgiu só, num quinto factor. No entanto, irá ser considerado na utilização da escala como um só factor, pois a sua remoção não altera o valor do alpha global.

Tabela 4: Comparação dos coeficientes alpha de Cronbach

\begin{tabular}{|c|c|c|c|c|c|c|}
\hline & $\begin{array}{c}\text { Lawrence e } \\
\text { colegas (2004) } \\
\end{array}$ & $\alpha^{5}$ & $\begin{array}{c}\text { Muncer } \\
\text { eLing (2006) } \\
\end{array}$ & $\alpha$ & Presente Estudo & $\alpha$ \\
\hline $\begin{array}{l}\text { Empatia } \\
\text { Cognitiva }\end{array}$ & $\begin{array}{c}1 / 19 / 25 / 26 / 36 / 41 / \\
44 / 52 / 54 / 55 / 58\end{array}$ & .84 & $25 / 26 / 44 / 52 / 54$ & .74 & $25 / 36 / 54 / 55 / 58$ & .80 \\
\hline $\begin{array}{l}\text { Reactividade } \\
\text { Emocional }\end{array}$ & $\begin{array}{c}6 / 21 / 22 / 27 / 29 / 32 / \\
42 / 43 / 48 / 50 / 59\end{array}$ & .76 & $6 / 27 / 32 / 50 / 59$ & .63 & $6 / 22 / 43 / 52 / 59$ & .71 \\
\hline $\begin{array}{l}\text { Capacidades } \\
\text { Sociais }\end{array}$ & $4 / 8 / 12 / 14 / 35 / 57$ & .57 & $4 / 8 / 12 / 14 / 35$ & .57 & $1 / 19 / 26 / 41 / 44$ & .70 \\
\hline $\begin{array}{l}\text { Dificuldades } \\
\text { Empáticas }\end{array}$ & - & - & - & - & $8 / 14 / 15 / 21 / 29 / 48$ & .66 \\
\hline
\end{tabular}

Comparativamente aos estudos de Lawrence e colaboradores (2004) e Muncer e Ling (2006), observa-se que os itens, que neste estudo saturam no factor das capacidades sociais, nos estudos referidos aparecem saturados no factor da empatia cognitiva (e.g., item 1: "Eu consigo, facilmente, dizer se alguém quer entrar numa conversa"). Esta observação não será de estranhar uma vez que as capacidades sociais parecem recorrer a uma certa noção de empatia cognitiva (Lawrence et al., 2004), pois ambas implicam a capacidade de julgamento. Por sua vez, os itens que neste estudo saturam no factor da empatia cognitiva, saturam no mesmo factor em ambos os estudos de comparação.

\footnotetext{
5 Os alphas indicados foram apresentados por Muncer e Ling (2006) quando reproduziram o estudo de Lawrence e colegas (2004), onde não foram encontrados os valores dos alphas.
} 
Os itens que saturam no factor das dificuldades empáticas, aparecem nos estudos de comparação distribuídos pelos factores da reactividade emocional $(21,29,48)$ e das capacidades sociais $(8,14)$, provavelmente porque apresentam dificuldades em termos de responder de forma adequada aos estados mentais de outras pessoas (e.g., item 21: "Para mim, é complicado ver porque algumas coisas chateiam tanto as pessoas"), e de avaliar espontaneamente situações sociais (e.g., item 8: "Eu considero difícil saber o que fazer numa situação social").

À excepção do item 52, os itens que neste estudo saturam no factor da reactividade emocional, saturam no mesmo factor em ambos os estudos de comparação. Nestes estudos o item 52 ("Eu consigo sintonizar-me com o que os outros sentem, rapidamente e intuitivamente") surge no factor da empatia cognitiva. No presente estudo o item 52 aparece saturado a 0.338 no factor das capacidades sociais, a 0.445 no factor da empatia cognitiva, e a 0.456 no factor da reactividade emocional. Pode ser considerado um item que traduz os três factores, ficando melhor incorporado na reactividade emocional, já que traduz uma "sintonização" com o que os outros pensam e sentem - uma resposta adequada aos estados mentais dos outros.

Note-se que nem todos os itens utilizados por Lawrence e colaboradores (2004) foram utilizados por Muncer e Ling (2006).

\section{Correlações}

$\mathrm{Na}$ análise de correlações entre variáveis é importante ter em consideração que, por convenção, $\mathrm{r}<.2$ aponta para uma associação muito baixa; entre .2 e .39 , baixa; entre .4 e .69 , moderada; entre .7 e .89 , alta; e entre .9 e 1, muito alta (Pestana e Gageiro, 2005).

Tabela 5: Matriz das correlações de Pearson entre as escalas e sub-escalas

\begin{tabular}{|c|c|c|c|c|c|c|}
\hline & 1. & 2. & 3. & 4. & 5. & 6. \\
\hline 1. $\mathrm{QE}$ & 1 & & & & & \\
\hline $\begin{array}{l}\text { 2. Empatia } \\
\text { Cognitiva }\end{array}$ & $.789^{* *}$ & 1 & & & & \\
\hline $\begin{array}{l}\text { 3. Reactivida- } \\
\text { de Emocional }\end{array}$ & $.777 * *$ & $.559 * *$ & 1 & & & \\
\hline $\begin{array}{l}\text { 4. Capacidades } \\
\text { Sociais }\end{array}$ & $.798 * *$ & $.606^{* *}$ & $.538 * *$ & 1 & & \\
\hline $\begin{array}{l}\text { 5. Dificuldades } \\
\text { Empáticas }\end{array}$ & $.634 * *$ & $.233 * *$ & $.297 * *$ & $.302 * *$ & 1 & \\
\hline 6. QS & $.235^{* *}$ & $.112^{*}$ & $.175^{* *}$ & $.207^{* *}$ & $.198^{* *}$ & 1 \\
\hline
\end{tabular}

** A correlação é significativa ao nível de 0.01 (2-tailed)

* A correlação é significativa ao nível de 0.05 (2-tailed) 
Como era de esperar, por medirem o mesmo constructo, foram encontradas correlações positivas significativas entre as três sub-escalas, e entre estas e a escala do Quociente de Empatia. Estes resultados, apesar de mais altos, vão de encontro aos valores de correlações encontrados por Lawrence e colegas (2004) e por Muncer e Ling (2006).

Observa-se uma correlação positiva entre a empatia cognitiva e as capacidades sociais $(r=.606)$; entre a empatia cognitiva e a reactividade emocional $(r=0.559)$; e entre as capacidades sociais e a reactividade emocional $(r=.538)$. Em 2004, Lawrence e colaboradores encontraram valores semelhantes ( $r=.25, r=.50, r=.21$, respectivamente), assim como Muncer e Ling em 2006 ( $r=.51, r=54, r=.17$, respectivamente).

Apesar de baixos valores de correlação, estes são positivos entre as dificuldades empáticas e as capacidades sociais $(r=.302)$, a reactividade emocional $(r=.297)$, e a empatia cognitiva $(r=.233)$.

Relativamente às correlações entre o Quociente de Sistematização e o Quociente de Empatia (e suas sub-escalas), estas foram surpreendentemente positivas $(r=.235)$. Os estudos realizados por Baron-Cohen e colegas (2003) e por Wakabayashi e colegas (2007), utilizando as versões originais do Quociente de Empatia e do Quociente de Sistematização, mostraram uma pequena correlação inversa entre as duas escalas no primeiro estudo $(r=-.16) \mathrm{e}$ uma correlação igualmente baixa no segundo estudo $(r=.06)$. Wakabayashi e colegas (2006), com a utilização das versões curtas utilizadas no presente estudo, observaram também uma pequena correlação inversa $(r=-.15)$. Estes resultados não estão em conformidade com a teoria da empatia - sistematização, pois de acordo com esta teoria os conceitos de empatia e de sistematização seriam relativos a dois tipos diferentes de cognição, sendo de esperar que a correlação entre eles fosse significativamente negativa.

\section{Conclusões}

De acordo com a teoria da empatia - sistematização (Baron-Cohen, 2002), o género feminino tem um tipo de cognição baseado na empatia, ao contrário do género masculino que possui um tipo de cognição baseado na sistematização. Apesar de esta teoria pressupor que estes dois tipos cognitivos são opostos, são muitos os estudos que não a suportam, encontrando baixas correlações negativas entre o quociente de empatia e o quociente de sistematização. O presente estudo encontrou inclusive uma correlação positiva, que apesar de baixa, sugere que estes dois tipos de cognição não são independentes. Neste sentido, em 2008, Andrew e os seus colaboradores apresentaram um estudo em que se observa que a correlação entre a escala do quociente de empatia e a escala Mach IV que avalia o maquiavelismo 
$(r=-.293)$ é mais alta do que a correlação entre o quociente de empatia e o quociente de sistematização $(r=-.17)$. De acordo com estes autores, o real opositor da empatia seria o maquiavelismo, pois enquanto os indivíduos empáticos apresentam uma preocupação emocional com os outros, os indivíduos maquiavélicos preocupam-se com o controlo emocional e com os seus próprios interesses.

Apesar dos resultados razoáveis encontrados através da análise factorial exploratória e da fiabilidade e consistência interna, é certo que o quociente de empatia avalia mais do que um factor, sendo por isso necessário que futuros estudos avaliem de forma rigorosa a sua estrutura e o conteúdo dos seus itens mediante a análise factorial confirmatória. Seria igualmente importante confirmar o modelo sugerido pelo presente estudo em que a escala do quociente de empatia apresentou quatro factores, bem como a verdadeira relação entre estes dois tipos de cognição, pois com os resultados aqui apresentados não é possível confirmar os pressupostos de base da teoria da empatia - sistematização.

\section{Anexos}

\section{Itens da Versão Curta do Quociente de Empatia}

1) Eu consigo, facilmente, dizer se alguém quer entrar numa conversa.

2) Eu gosto realmente de me preocupar com as outras pessoas.

3) Eu considero difícil saber o que fazer numa situação social.

4) Frequentemente tenho dificuldades em julgar se algo é rude ou delicado.

5) Numa conversa, eu tendo a focar-me nos meus pensamentos em vez de me focar no que o meu ouvinte possa estar a pensar.

6) Eu consigo perceber rapidamente quando alguém diz uma coisa mas quer dizer outra.

7) Para mim, é complicado ver porque algumas coisas chateiam tanto as pessoas.

8) É fácil, para mim, colocar-me no lugar de outra pessoa.

9) Eu sou bom a predizer como alguém se irá sentir.

10) Eu vejo com facilidade quando alguém, num grupo, se está a sentir embaraçado ou desconfortável.

11) Nem sempre consigo perceber porque alguém se terá sentido ofendido por um reparo.

12) Não tendo a achar as situações sociais confusas.

13) As outras pessoas dizem-me que sou bom a perceber como elas se sentem ou o que estão a pensar. 
14) Eu consigo perceber com facilidade quando alguém está interessado ou aborrecido com o que estou a dizer.

15) Normalmente os meus amigos falam-me dos seus problemas e dizem que sou muito compreensivo.

16) Eu percebo quando estou a ser intrometido mesmo que a outra pessoa não mo diga.

17) Frequentemente as outras pessoas dizem que sou insensível, se bem que nem sempre percebo porquê.

18) Eu consigo sintonizar-me com o que os outros sentem, rapidamente e intuitivamente.

19) Eu consigo descobrir rapidamente o assunto sobre o que outra pessoa quer falar.

20) Eu consigo perceber quando outra pessoa está a disfarçar os seus verdadeiros sentimentos.

21) Eu sou bom a prever o que outra pessoa irá fazer.

22) Eu tendo a envolver-me emocionalmente com os problemas dos meus amigos.

\section{Itens da Versão Curta do Quociente de Sistematização}

1) Se estivesse a comprar um carro, quereria obter informação específica acerca da sua cilindrada.

2) Se houvesse um problema com as ligações eléctricas em minha casa, eu seria capaz de o resolver sozinho(a).

3) Raramente leio artigos ou páginas web sobre novas tecnologias.

4) Não aprecio jogos que envolvam um elevado grau de estratégia.

5) Fascina-me a forma como as máquinas trabalham.

6) Em matemática, fico intrigado(a) com as regras e os padrões que governam os números.

7) Acho difícil entender os manuais de instruções quando servem para conectar objectos eléctricos.

8) Se estivesse a comprar um computador, quereria saber os detalhes exactos acerca da capacidade da sua unidade de disco rígido e da velocidade do processador.

9) Acho difícil ler e entender mapas.

10) Quando olho para uma peça de mobiliário, não reparo nos detalhes de como foi construída.

11) Acho difícil aprender a orientar-me numa nova cidade.

12) Não tenho a tendência de ver documentários científicos na televisão nem de ler artigos acerca da ciência e da natureza.

13) Se estivesse a comprar uma aparelhagem, quereria saber acerca das suas características técnicas precisas. 
14) Acho fácil compreender exactamente como funcionam as probabilidades nas apostas.

15) Não sou muito meticuloso(a) quando realizo uma tarefa do tipo "faça você próprio".

16) Quando olho para um edifício, fico curioso sobre a forma precisa de como foi construído.

17) Acho difícil entender a informação que o banco me manda acerca de diferentes investimentos e sistemas de poupança.

18) Quando viajo de comboio, frequentemente pergunto-me como são exactamente coordenadas as redes ferroviárias.

19) Se estivesse a comprar uma câmara, não olharia com atenção para a qualidade da lente.

20) Quando ouço a previsão do tempo, não estou muito interessado(a) nos padrões meteorológicos.

21) Quando olho para uma montanha, penso em como precisamente ela foi formada.

22) Posso facilmente visualizar como as auto-estradas na minha região se articulam.

23) Quando estou num avião, não penso sobre as aerodinâmicas.

24) Estou interessado(a) em saber o caminho que um rio toma da sua fonte até ao mar.

25) Não estou interessado(a) em entender como funciona a comunicação sem fios.

\section{Referências}

Andrew, J., Cooke, M., \& Muncer, S. J. (2008). The relationship between empathy and Machiavellianism: An alternative to empathizing-systemizing theory. Personality and Individual Differences, 44, 1203-1211.

Baron-Cohen, S. (2002). The extreme male brain theory of autism. Trends in Cognitive Sciences, 6, 248-254.

Baron-Cohen, S., Richler, J., Bisarya, D., Gurunathan, N., \& Wheelwright, S. (2003). The Systemizing Quotient (SQ): An investigation of adults with Asperger syndrome or high functioning autism and normal sex differences. Philosophical Transactions of the Royal Society, Series B, Special issue on "Autism: Mind and Brain," 358, 361-374.

Baron-Cohen, S., \& Wheelwright, S. (2004). The empathy quotient: an investigation of adults with Asperger syndrome or high functioning autism, and normal sex differences. Journal of Autism and Developmental Disorders, 34 (2), 163-175.

Batson, C. D., Fultz, J., \& Schoenrade, P. A. (1987). Distress and empathy: Two qualitatively distinct vicarious emotions with different motivational consequences. Journal of Personality, 55, 19-39. 
Davis, M. H. (1980). A multidimensional approach to individual differences in empathy. Catalog of Selected Documents in Psychology, 10, 85.

Hakansson, J. (2003). Exploring the phenomenon of empathy. Ph.D. Thesis, Stockholm University.

Köhler, W. (1992). Behavior. In L. Köhler (Ed.), Gestalt Psychology: The definitive statement of the gestalt theory. New York: Liveright Publishing Corporation.

Lawrence, E. J., Shaw, P., Baker, D., Baron-Cohen, S., \& David, A. S. (2004). Measuring empathy: reliability and validity of the Empathy Quotient. Psychological Medicine, 34, 911-924.

Mead, G. H. (1982). Espiritu, persona y sociedad: Desde el punto de vista del conductismo social (Germani, G., Trad.). Barcelona: Ediciones Paidós Ibérica.

Muncer, S. J., \& Ling, J. (2006). Psychometric analysis of the empathy quotient (EQ) scale. Personality and Individual Differences, 40, 1111-1119.

Pestana, M. H., \& Gageiro, J. N. (2005). Descobrindo a regressão: Com a complementaridade do SPSS ( $1^{\mathrm{a}}$ ed.). Lisboa: Edições Sílabo.

Reis, E. (2001). Estatística multivariada aplicada (2ª ed.). Lisboa: Edições Sílabo.

Wakabayashi, A., Baron-Cohen, S., Uchiyama, T., Yoshida, Y., Kuroda, M., \& Wheelwright, S. (2007). Empathizing and systemizing in adults with and without autism spectrum conditions: Cross-cultural stability. Journal of Autism and Developmental Disorders, 37, 1823-1832.

Wakabayashi, A., Baron-Cohen, S., Wheelwright, S., Goldenfeld, N., Delaney, J., Fine, D., Smith, R., \& Weil, L. (2006). Development of short forms of the empathy quotient (EQ-Short) and the systemizing quotient (SQ-Short). Personality and Individual Differences, 41, 929-940.

Wellman, H. M. (1990). First steps in the child's theorizing about the mind. In J. W. Astington, P. L. Harris, \& D. R. Olson (Eds.), Developing theories of mind (pp. 64-92). Canada: Cambridge University Press. 